\title{
Analisa Pengendalian Kualitas Produk Karung Goni Plastik \\ Dengan Menggunakan Metode Six Sigma \\ Pada PT. XYZ
}

\author{
*Kamil Mustafa, Sutrisno \\ Program Studi Teknik Industri, Fakultas Teknik \\ Universitas Medan Area, Indonesia \\ *Email : kamust99@yahoo.com
}

\begin{abstract}
Abstrak
Pengendalian kualitas produk yaitu suatu proses yang dibuat untuk menjaga supaya realisasi sesuai dengan yang direncanakan. PT. XYZ adalah perusahaan yang bergerak di bidang pengolahan bijih plastik sebagai bahan baku utama untuk menjadi karung goni plastik yang digunakan untuk berbagai keperluan industri maupun infrastruktur. Dalam kegiatan produksinya, setiap bulannya terdapat persentase produk cacat sebesar $6,59 \%-9,67 \%$. Penelitian ini bertujuan untuk mengetahui faktor penyebab kecacatan produk serta menganalisis hubungan antara cacat yang terjadi dengan kualitas produksi dan memberikan usulan perbaikan dengan menggunakan metode Six Sigma melalui tahap DMAIC (Define, Measure, Analyze, Improve, Control). Hasil penelitian ini menunjukkan bahwa ada beberapa jenis kecacatan pada produk karung goni plastik yang sering terjadi diantaranya adalah jahitan miring dan cetakan miring, yang disebabkan oleh komposisi bahan baku yang tidak sesuai, kelalaian operator, keandalan mesin dan metode kerja yang tidak sesuai. Berdasarkan hasil analisa regresi linier diperoleh hubungan yang kuat antara jumlah cacat dengan kualitas produksi masing-masing sebesar 39\%, artinya cacat jahitan miring dan cacat cetakan miring memberikan kontribusi sebesar 39\% terhadap kegagalan produk, sedangkan sisanya dipengaruhi oleh variabel lain yang tidak disebutkan dalam penelitian ini.
\end{abstract}

Kata Kunci: Cetakan Miring, Jahitan Miring, Pengendalian kualitas, Six Sigma.

\begin{abstract}
The product quality control is a process of maintaining all the efforts are realized as planned as to the company. PT XYZ is a company runs in the field of processing plastic ore as the main material in producing the plastic jute sack for industrial purposes, even infrastructure. The defective products percentage as much as $6.59 \%-9.67 \%$ occurs in the production activities every month. The research aims to discover factors that causing the defective products along with analyzing the relationship between the defective towards quality product and provide suggestions to improve by utilizing Six Sigma method. The method is used to DMAIC phase (Define, Measure, Analyze, Improve, and Control). The result reveals that the defectives on plastic jute sack usually occur on the sloped of seams and mold. This is due to several cases such as unmatched of materials composition, operator negligence, machine's reliability, and inappropriate working method. Based on the linear regression analysis, a robust relationship has been found between total defective of product and quality product as much as 39\% respectively. This indicates that sloped of seams and mold give the contribution about 39\% towards product failure. Meanwhile, for the rest elements might be contributed by other variables which are not included in the study.
\end{abstract}

Keywords: Quality Control, Six Sigma, Sloped Mold, Sloped Seams. 


\section{PENDAHULUAN}

Pemahaman kualitas sangat penting dalam pengembangan aktifitas perusahaan sebab pertumbuhan suatu perusahaan sangat ditentukan oleh kualitas produk atau jasa yang dihasilkan. Ketidakpedulian terhadap kualitas akan menyebabkan terjadinya kehilangan peluang menjual produk dan pangsa pasar yang akhirnya berakibat pada penurunan aktifitas dan pertumbuhan perusahaan. PT. XYZ adalah perusahaan yang bergerak di bidang pengolahan bijih plastik sebagai bahan baku utama untuk menjadi karung goni plastik yang digunakan untuk berbagai keperluan industri maupun infrastruktur.

Berdasarkan hasil wawancara dengan pihak manajemen perusahaan, kecacatan produk karung goni plastik sering kali terjadi dan hal ini sangat mempengaruhi produktifitas perusahaan dan berdampak terhadap keuntungan yang didapat perusahaan. Dimana setiap bulannya persentase produk cacat sebesar $6,59 \%-9,67 \%$. Sementara batas toleransi tingkat kecacatan sebesar 3\%-4\% perbulannya. Jenis kecacatan pada produk karung goni plastik di PT. XYZ yang dominan terjadi diantaranya adalah jahitan miring dengan persentase cacat perbulan sebesar 8,37\% - 9,67\%, dan cetakan miring sebesar 6,59\%-7,93\% perbulan, yang disebabkan oleh komposisi bahan baku yang tidak sesuai, kelalaian operator, keandalan mesin dan metode kerja yang tidak sesuai.
Berdasarkan uraian diatas, maka dapat diketahui bahwa masalah pengendalian kualitas terhadap kualitas produk yang dihasilkan oleh perusahaan merupakan hal yang penting dan membutuhkan kajian yang lebih mendalam. Oleh karena itu penulis menganggap penelitian dibidang pengendalian kualitas ini sangat penting dalam mendukung perusahaan untuk memiliki daya saing dengan produk perusahaan lain. Dalam hal ini bentuk penelitian tentang analisa pengendalian kualitas karung goni plastik dengan menggunakan metode six sigma.

Rumusan masalah pada penelitian ini adalah sebagai berikut :

1. Apa saja faktor-faktor penyebab kecacatan produk karung goni plastik yang dapat mempengaruhi kualitas karung tersebut ?

2. Bagaimana hubungan antara jumlah produksi terhadap jumlah cacat jahitan miring dan cacat cetakan miring produksi karung goni plastik ?

Adapun tujuan dari penelitian ini adalah sebagai berikut :

1. Untuk mengetahui faktor penyebab kecacatan tertinggi untuk segera diperbaiki.

2. Untuk menganalisis hubungan antara cacat jahitan miring dan cacat cetakan miring terhadap kualitas produksi dengan menggunakan metode six sigma. 
3. Memberi usulan dan alternatif dalam menjaga kualitas produk untuk memperkecil faktor penyebab kecacatan produk sehingga perusahaan tidak mengalami kerugian.

Menurut Vincent Gasperz dalam jurnal (Johnson Saragih, Winnie Septianie, Yuliana, 2011), kata kualitas memiliki banyak definisi yang berbeda, dan bervariasi dari yang konvensional sampai yang bersifat strategik. Hal ini disebabkan karena pengertian kualitas dapat diterapkan pada berbagai bidang kehidupan. Definisi konvensional dari kualitas biasanya menggambarkan karakteristik langsung dari suatu produk seperti : performansi (performance), keandalan (reliability), mudah dalam penggunaan (easy of use), estetika (esthetics), dan sebagainya. Sedangkan secara strategik, menyatakan bahwa kualitas adalah segala sesuatu yang mampu memenuhi keinginan atau kebutuhan pelanggan (meeting the needs of customers).

Pengendalian kualitas merupakan suatu sistem verifikasi dan penjagaan atau perawatan dari suatu tingkat atau derajat kualitas produk atau proses yang dikehendaki dengan perencanaan yang seksama, pemakaian peralatan yang sesuai, inspeksi yang terus menerus serta tindakan korektif bilamana diperlukan. Jadi, pengendalian kualitas tidak hanya kegiatan inspeksi ataupun menetukan produk itu baik atau jelek (Ginting, 2007).
Six Sigma adalah merupakan suatu visi peningkatan kualitas menuju target 3,4 kegagalan per sejuta kesempatan (defect per milion opportunity) untuk setiap transaksi produk (barang atau jasa), upaya giat menuju kesempurnaan / zero defect (Gaspersz, 2002).

Menurut Pyzdek dalam jurnal (Yogi Yusuf Wibisono, Theressa Suteja, 2013) six sigma merupakan implementasi dari prinsip dan teknik mutu yang terstruktur, fokus, dan efektif yang ditujukan untuk mencapai performansi bisnis yang bebas dari kesalahan dimana performansi bisnis diukur dari level sigma.

Dalam perspektif manajemen, six sigma merupakan sebagai alat untuk merubah budaya perusahaan, diantaranya adalah pendekatan perancangan, proses dan solusi masalah, pendayagunaan data, cara untuk mencapai efesiensi dan disiplin, memuaskan pelanggan, peningkatan keuntungan perusahaan/mengurangi biaya dan membentuk nilai positif perusahaan dalam bisnis. Sedangkan dalam perspektif kekuatan kerja, six sigma itu adalah : keahlian khusus/kepemimpinan, keahlian teknis, berpikir secara proses, mengaitkan nilai statistik dan manajemen, sistematiskan proses, disiplin solusi masalah, efesiensi operasional, mengurangi ketidakbergunaan, pengakuan dan penghargaan (Muis, 2011).

Six sigma merupakan pendekatan untuk menyelesaikan masalah dalam 
peningkatan proses melalui fase DMAIC (Define, Measure, Analyze, Improve, Control). DMAIC adalah metodologi kualitas terkendali data untuk memperbaiki produk atau proses dapat ditingkatkan untuk memenuhi atau menambah persyaratan/kebutuhan konsumen dengan mendukung tujuan bisnis. Konsep DMAIC merupakan sebuah closed loop dimana output dari tiap fase akan menjadi input bagi fase selanjutnya (Remba Yanuar Efranto, Falih Suaedi, 2011).

\section{METODE PENELITIAN}

Penelitian ini bersifat eksperimen (Experimental Research) yaitu penelitian yang bertujuan untuk menyelidiki hubungan sebab akibat dan berapa besar hubungan tersebut dengan mengenakan perlakuan pada satu atau lebih kelompok eksperimen dan membandingkan hasilnya dengan satu atau lebih kelompok yang tidak dikenakan perlakuan (Sugiyono, 2014).

Kerangka berpikir dalam penelitian ini dapat dilihat pada gambar 1 yang menunjukkan hubungan antara variabel bebas dengan variabel terikat.

Gambar 1. Kerangka Berpikir

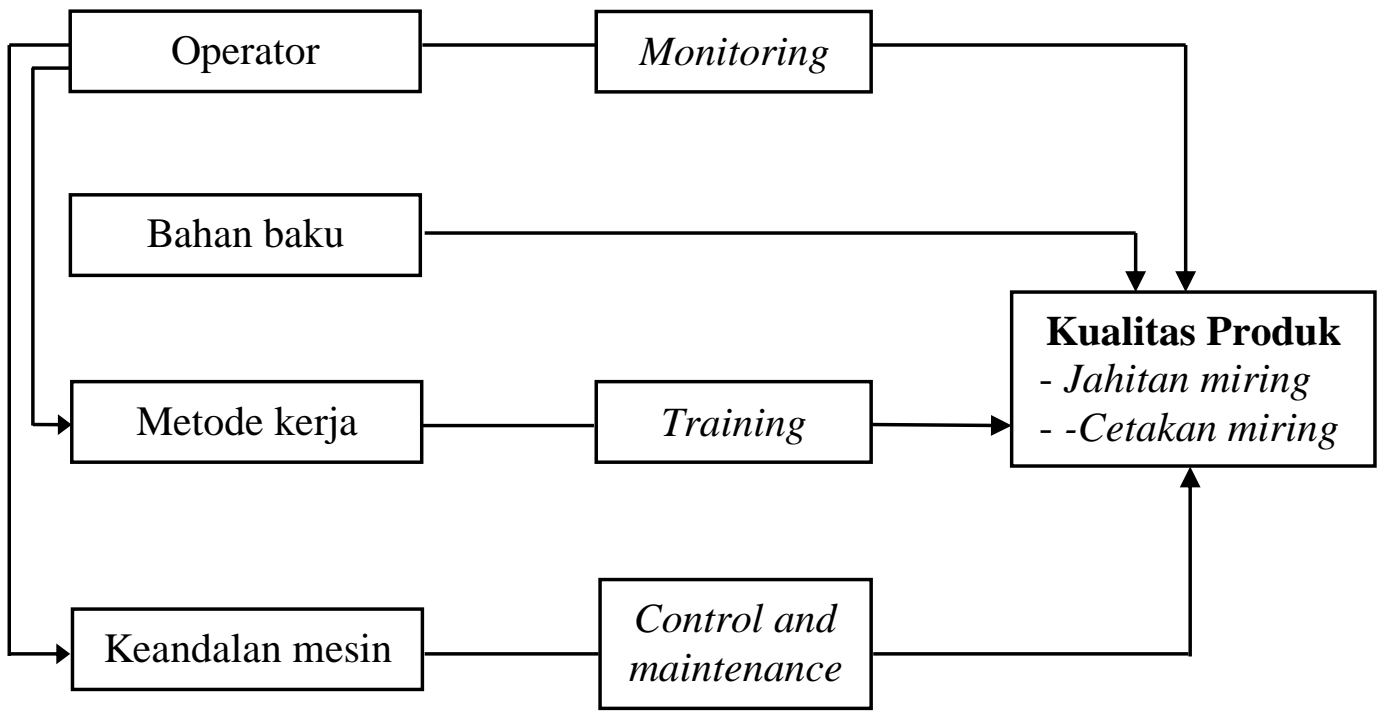

Sumber : Pengolahan data

Tahapan-tahapan metode Six Sigma (DMAIC) yang dilakukan dalam penelitian ini adalah sebagai berikut :

\section{Tahap Define (Perumusan)}

Fase menentukan/mendefinisikan masalah, kemudian merumuskan apa saja yang harus dilakukan untuk menetapkan masalah dan mengukur masalah yang sering terjadi dengan tujuan agar dapat mengambil langkah yang efektif untuk mengurangi produk yang cacat.

2. Tahap Measure (Pengukuran)

Setelah menemukan CTQ atau garis besar masalah kemudian mengukur masalah yang sering terjadi dengan menggunakan data perbandingan produksi 
karung goni plastik dibandingkan persentase kecacatan yang terjadi, hal ini dilakukan untuk mengukur sejauh mana efektifitas perusahaan untuk mengurangi produk cacat.

\section{Tahap Analyze (Analisis)}

Dimana hasil yang diperoleh dari fase ini adalah berupa informasi atau pernyataan mengenai sebab-sebab terjadinya cacat yang harus segera diperbaiki. Fokus pada fase ini adalah pertanyaan mengapa cacat, kesalahan atau variasi yang berlebihan terjadi. Alat yang digunakan untuk menganalisis adalah diagram tulang ikan dan diagram pareto, dengan menggunakan dua alat analisis ini dapat diketahui kecacatan yang sering terjadi dan faktor penyebab kecacatan sehingga dapat mengetahui mengapa terjadi kecacatan.
4. Tahap Improve (Perbaikan)

Tahap perbaikan merupakan tahapan penentuan tindakan-tindakan perbaikan yang ditujukan untuk mengurangi akar masalah sehingga bias menghasilkan peningkatan yang signifikan terkait pengurangan produk cacat.

\section{Tahap Control}

Setelah hasil analisis dan improve perlu dibuat sistem dengan tujuan mengendalikan terhadap proses supaya tidak terulang kesalahan yang sama dan juga untuk meningkatkan kapabilitas proses menuju target six sigma.

\section{HASIL DAN PEMBAHASAN}

Berikut data jumlah produksi dan jumlah produk cacat April 2016 s/d Maret 2017 dapat dilihat pada tabel 1.

Tabel 1. Data Jumlah Produksi Dan Jumlah Produk Cacat April 2016 s/d Maret 2017.

\begin{tabular}{lcccccc}
\hline \multicolumn{1}{c}{ Bulan } & $\begin{array}{c}\text { Jumlah } \\
\text { Produksi } \\
\text { (Unit) }\end{array}$ & $\begin{array}{c}\text { Jahitan } \\
\text { Miring } \\
\text { (Unit) }\end{array}$ & \% & $\begin{array}{c}\text { Jenis Cacat } \\
\text { Miring } \\
\text { (Unit) }\end{array}$ & \% & Total (Unit) \\
\hline April & 1.628 .983 & 136.969 & 8,41 & 107.328 & 6,59 & 244.297 \\
Mei & 1.706 .511 & 147.826 & 8,66 & 118.185 & 6,93 & 266.011 \\
Juni & 1.631 .559 & 148.018 & 9,07 & 118.378 & 7,26 & 266.396 \\
Juli & 1.654 .800 & 138.690 & 8,38 & 109.050 & 6,59 & 247.740 \\
Agustus & 1.707 .939 & 153.619 & 8,99 & 123.979 & 7,26 & 277.598 \\
September & 1.700 .934 & 158.776 & 9,33 & 129.135 & 7,59 & 287.911 \\
Oktober & 1.696 .086 & 164.058 & 9,67 & 134.417 & 7,93 & 298.475 \\
November & 1.633 .525 & 142.717 & 8,74 & 113.077 & 6,92 & 255.794 \\
Desember & 1.632 .812 & 137.224 & 8,40 & 107.585 & 6,59 & 244.809 \\
Januari & 1.661 .134 & 139.112 & 8,37 & 109.473 & 6,59 & 248.585 \\
Februari & 1.679 .145 & 151.507 & 9,02 & 121.867 & 7,26 & 273.374 \\
Maret & 1.628 .937 & 153.256 & 9,41 & 123.615 & 7,59 & 276.871 \\
\hline Total & $\mathbf{1 9 . 9 6 2 . 3 6 5}$ & $\mathbf{1 . 7 7 1 . 7 7 2}$ & & $\mathbf{1 . 4 1 6 . 0 8 9}$ & & $\mathbf{3 . 1 8 7 . 8 6 1}$ \\
\hline Sumber $:$ Pen & & & & &
\end{tabular}

Sumber : Pengolahan data 
Pengolahan data pada penelitian ini menggunakan pendekatan DMAIC. Pendekatan tersebut akan dijabarkan secara bertahap sebagai berikut :

\section{Tahap Define (Perumusan)}

Pelaksanaan proyek Six Sigma dilakukan setelah menentukan tujuan dan kriteria dari proyek Six Sigma. Tujuan dari pelaksanaan proyek Six Sigma adalah meningkatkan kualitas dari produk karung goni plastik dengan cara mengurangi kecacatan produk sampai tingkatan terendah dengan mengendalikan faktorfaktor yang menyebabkan kecacatan (defect) produk tersebut.

Penentuan Karakteristik Kualitas (Critical to Quality/CTQ). Dalam proyek Six Sigma, jenis dari kecacatan disebut dengan CTQ merupakan atribut-atribut yang sangat penting untuk diperhatikan karena berkaitan langsung dengan kebutuhan dan kepuasan pelanggan. Pada penelitian ini yang menjadi CTQ yaitu kecacatan jahitan miring dan kecacatan cetakan miring.

\section{Tahap Measure (Pengukuran)}

Penentuan Batas Kontrol (P-Chart) untuk Cacat Jahitan Miring. Pengukuran dilakukan dengan statistical quality control jenis P-Chart. Peta kontrol dibuat untuk mengetahui apakah proses dalam kendali dan untuk memonitor variasi proses secara terus menerus. Peta $\mathrm{P}$ menggambarkan bagian yang ditolak karena tidak sesuai dengan spesifikasi yang diinginkan. Berikut contoh perhitungan nilai $\overline{\mathrm{P}}(\mathrm{CL})$ :

$$
\begin{aligned}
& \overline{\mathrm{p}}=\frac{\Sigma \mathrm{np}}{\Sigma \mathrm{n}}=\frac{1.771 .772}{19.962 .365}=0,089 \\
& \mathrm{UCL}=\overline{\mathrm{p}}+3 \sqrt{\frac{\overline{\mathrm{p}(1-\overline{\mathrm{p}})}}{n}} \\
& \mathrm{LCL}=\overline{\mathrm{p}}-3 \sqrt{\frac{\overline{\bar{p}(1-\overline{\mathrm{p}})}}{n}}
\end{aligned}
$$

Untuk perhitungan UCL dan LCL adalah sebagai berikut :

$$
\begin{aligned}
\mathrm{UCL} & =0,089+3 \sqrt{\frac{0,089(1-0,089)}{12}} \\
& =0,336 \\
\mathrm{LCL} & =0,089-3 \sqrt{\frac{0,089(1-0,089)}{12}} \\
& =-0,158 \approx 0
\end{aligned}
$$

Nilai minus pada LCL sama dengan nol artinya bahwa tidak ada kecacatan per produk unit yang nilainya minus.

Keterangan :

$\mathrm{n} \quad$ : total produksi (sampel) yang diperiksa.

¿np : total produk cacat jahitan miring

$\mathrm{P} \quad$ : proporsi

$\overline{\mathrm{P}}(\mathrm{CL})$ : rata-rata proporsi

UCL : Upper Control Limit (batas kontrol atas)

LCL : Lower Control Limit (batas kontrol bawah)

Perhitungan batas kendali untuk 12 bulan kecacatan jahitan miring dapat dilihat pada tabel 2 . 
Tabel 2. Perhitungan Nilai $\bar{P}(C L)$, UCL, LCL Cacat Jahitan Miring

\begin{tabular}{ccccccc}
\hline No. & $\begin{array}{c}\text { Total } \\
\text { Produksi } \\
\text { (unit) }\end{array}$ & $\begin{array}{c}\text { Total Cacat } \\
\text { Jahitan Miring } \\
\text { (unit) }\end{array}$ & $\overline{\mathrm{P}}(\mathbf{C L})$ & $\mathbf{U C L}$ & $\mathbf{L C L}$ & Keterangan \\
\hline 1 & 1.628 .983 & 136.969 & 0,089 & 0,336 & 0 & In control \\
2 & 1.706 .511 & 147.826 & 0,089 & 0,336 & 0 & In control \\
3 & 1.631 .559 & 148.018 & 0,089 & 0,336 & 0 & In control \\
4 & 1.654 .800 & 138.690 & 0,089 & 0,336 & 0 & In control \\
5 & 1.707 .939 & 153.619 & 0,089 & 0,336 & 0 & In control \\
6 & 1.700 .934 & 158.776 & 0,089 & 0,336 & 0 & In control \\
7 & 1.696 .086 & 164.058 & 0,089 & 0,336 & 0 & In control \\
8 & 1.633 .525 & 142.717 & 0,089 & 0,336 & 0 & In control \\
9 & 1.632 .812 & 137.224 & 0,089 & 0,336 & 0 & In control \\
10 & 1.661 .134 & 139.112 & 0,089 & 0,336 & 0 & In control \\
11 & 1.679 .145 & 151.507 & 0,089 & 0,336 & 0 & In control \\
12 & 1.628 .937 & 153.256 & 0,089 & 0,336 & 0 & In control \\
\hline $\mathbf{\Sigma}$ & $\mathbf{1 9 . 9 6 2 . 3 6 5}$ & $\mathbf{1 . 7 7 1 . 7 7 2}$ & & & & \\
\hline
\end{tabular}

Sumber : Pengolahan data

Tabel 3. Perhitungan Nilai $\overline{\mathrm{P}}(\mathrm{CL})$, UCL, LCL Cacat Cetakan Miring

\begin{tabular}{ccccccc}
\hline No. & $\begin{array}{c}\text { Jumlah } \\
\text { Produksi } \\
\text { (unit) }\end{array}$ & $\begin{array}{c}\text { Jumlah Cacat } \\
\text { Cetakan Miring } \\
\text { (unit) }\end{array}$ & CL & UCL & LCL & Keterangan \\
\hline 1 & 1.628 .983 & 107.328 & 0,071 & 0,293 & 0 & In control \\
2 & 1.706 .511 & 118.185 & 0,071 & 0,293 & 0 & In control \\
3 & 1.631 .559 & 118.378 & 0,071 & 0,293 & 0 & In control \\
4 & 1.654 .800 & 109.050 & 0,071 & 0,293 & 0 & In control \\
5 & 1.707 .939 & 123.979 & 0,071 & 0,293 & 0 & In control \\
6 & 1.700 .934 & 129.135 & 0,071 & 0,293 & 0 & In control \\
7 & 1.696 .086 & 134.417 & 0,071 & 0,293 & 0 & In control \\
8 & 1.633 .525 & 113.077 & 0,071 & 0,293 & 0 & In control \\
9 & 1.632 .812 & 107.585 & 0,071 & 0,293 & 0 & In control \\
10 & 1.661 .134 & 109.473 & 0,071 & 0,293 & 0 & In control \\
11 & 1.679 .145 & 121.867 & 0,071 & 0,293 & 0 & In control \\
12 & 1.628 .937 & 123.615 & 0,071 & 0,293 & 0 & In control \\
\hline $\mathbf{\Sigma}$ & $\mathbf{1 9 . 9 6 2 . 3 6 5}$ & $\mathbf{1 . 4 1 6 . 0 8 9}$ & & & & \\
\hline Sund
\end{tabular}

Sumber : Pengolahan data

Hasil perhitungan batas kendali Defect Per Million Opportunity untuk 12 bulan kecacatan cetakan miring dengan menggunakan rumus yang sama, dapat dilihat pada tabel 3 . (DPMO) adalah ukuran kegagalan dalam proyek peningkatan kualitas Six Sigma, yang menunjukkan kegagalan per sejuta kesempatan. 
DPMO $=\frac{\text { Jumlah Cacat }}{\text { Banyak sampel } \times \text { Jumlah CTQ }} \times 10^{6}$

Sebagai contoh untuk perhitungan DPMO pada bulan April 2016.

$$
\begin{aligned}
\text { DPMO } & =\frac{244.297}{1.628 .983 \times 2} \times 10^{6} \\
& =\frac{244.297}{1.628 .983 \times 2} \times 10^{6} \\
& =74.984,51
\end{aligned}
$$

Sedangkan untuk nilai sigma adalah ukuran kinerja perusahaan yang menggambarkan kemampuan dalam menghasilkan produk bebas cacat. Contoh perhitungan nilai sigma untuk bulan April 2016, penentuan nilai Sigma menggunakan Microsoft Excel dengan formulasi :

$$
\text { Nilai } \begin{aligned}
\sigma & =\text { Normsinv }\left(\frac{1.000 .000-\text { DPMO }}{1.000 .000}\right)+1,5 \\
& =\text { Normsinv }\left(\frac{1.000 .000-74.984,51}{1.000 .000}\right)+1,5 \\
& =2.9396
\end{aligned}
$$

Tabel 4. Nilai DPMO dan nilai Six Sigma produk karung goni plastik

\begin{tabular}{clccccc}
\hline No & Bulan & $\begin{array}{c}\text { Jumlah } \\
\text { Produksi } \\
\text { (Unit) }\end{array}$ & $\begin{array}{c}\text { Jumlah } \\
\text { Cacat } \\
\text { (Unit) }\end{array}$ & $\begin{array}{c}\text { Jumlah } \\
\text { CTQ }\end{array}$ & DPMO & Nilai $\boldsymbol{~}$ \\
\hline 1 & April & $1,628,983$ & 244,297 & 2 & $74,984.51$ & 2.9396 \\
2 & Mei & $1,706,511$ & 266,011 & 2 & $77,940.02$ & 2.9191 \\
3 & Juni & $1,631,559$ & 266,396 & 2 & $81,638.48$ & 2.8941 \\
4 & Juli & $1,654,800$ & 247,740 & 2 & $74,854.97$ & 2.9406 \\
5 & Agustus & $1,707,939$ & 277,598 & 2 & $81,266.95$ & 2.8966 \\
6 & September & $1,700,934$ & 287,911 & 2 & $84,633.21$ & 2.8746 \\
7 & Oktober & $1,696,086$ & 298,475 & 2 & $87,989.35$ & 2.8532 \\
8 & November & $1,633,525$ & 255,794 & 2 & $78,295.10$ & 2.9166 \\
9 & Desember & $1,632,812$ & 244,809 & 2 & $74,965.46$ & 2.9398 \\
10 & Januari & $1,661,134$ & 248,585 & 2 & $74,823.89$ & 2.9408 \\
11 & Februari & $1,679,145$ & 273,374 & 2 & $81,402.74$ & 2.8957 \\
12 & Maret & $1,628,937$ & 276,871 & 2 & $84,985.18$ & 2.8723 \\
\hline $\boldsymbol{\Sigma}$ & & $\mathbf{1 9 , 9 6 2 , 3 6 5}$ & $\mathbf{3 , 1 8 7 , 8 6 1}$ & & $\mathbf{9 5 7 , 7 7 9 . 8 5}$ & $\mathbf{3 4 . 8 8 3 0}$ \\
\hline Rata-rata & & & $\mathbf{7 9 , 8 1 4 . 9 9}$ & $\mathbf{2 . 9 0 6 9}$ \\
\hline
\end{tabular}

Sumber : Pengolahan data

\section{Tahap Analyze (Analisis)}

Jumlah CTQ pada produk karung goni plastik pada PT. XYZ terdapat 2 CTQ potensial yang dapat menyebabkan kecacatan pada produk. Untuk itu CTQ yang memiliki persentase yang sangat besar adalah CTQ yang paling dominan.
Adapun perhitungan mengenai persentase cacat dengan jenis cacat jahitan miring dapat dilihat dibawah ini.

$$
\begin{gathered}
\% \text { Cacat }=\frac{\text { Jumlah cacat per CTQ }}{\text { Jumlah cacat total }} \times 100 \% \\
=\frac{1.771 .772}{3.187 .861} \times \\
=55,58
\end{gathered}
$$

Tabel 5. Persentase CTQ potensial produk karung goni plastik 


\begin{tabular}{llccc}
\hline No. & Jenis kecacatan & $\begin{array}{c}\text { Jumlah } \\
\text { (unit) }\end{array}$ & \% CTQ & Persentase kumulatif (\%) \\
\hline 1 & Jahitan miring & 1.771 .772 & 55,58 & 55,58 \\
2 & Cetakan miring & 1.416 .089 & 44,42 & 100 \\
\hline & Total & $\mathbf{3 . 1 8 7 . 8 6 1}$ & $\mathbf{1 0 0}$ & \\
\hline
\end{tabular}

Sumber : Pengolahan data

Dari tabel diatas, maka dapat dibuat pareto diagram untuk kecacatan produk karung goni plastik yang dapat dilihat pada gambar 2 berikut ini :

Gambar 2. Diagram Pareto Penyebab Kecacatan Produk Karung Goni Plastik

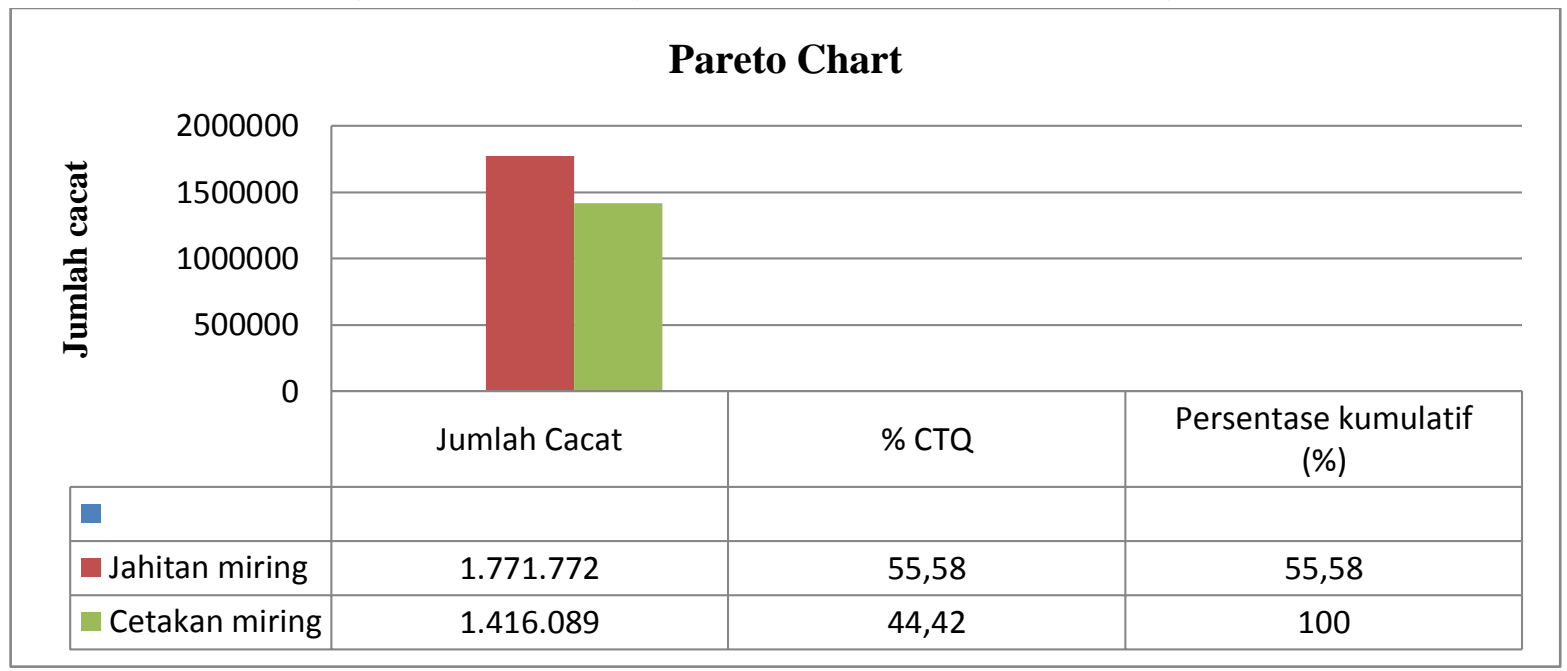

Sumber : Pengolahan data

Tabel 6. Perhitungan Korelasi Jahitan Miring vs Jumlah Produksi

\begin{tabular}{cccccc}
\hline No. & $\begin{array}{c}\text { Jumlah } \\
\text { Produksi } \\
(\mathbf{X})\end{array}$ & $\begin{array}{c}\text { Jahitan } \\
\text { Miring } \\
(\mathbf{Y})\end{array}$ & $\mathbf{X} * \mathbf{Y}$ & $\mathbf{X}^{\mathbf{2}}$ & $\mathbf{Y}^{\mathbf{2}}$ \\
\hline 1 & $1,628,983$ & 136,969 & $223,120,172,527$ & $2,653,585,614,289$ & $18,760,506,961$ \\
2 & $1,706,511$ & 147,826 & $252,266,695,086$ & $2,912,179,793,121$ & $21,852,526,276$ \\
3 & $1,631,559$ & 148,018 & $241,500,100,062$ & $2,661,984,770,481$ & $21,909,328,324$ \\
4 & $1,654,800$ & 138,690 & $229,504,212,000$ & $2,738,363,040,000$ & $19,234,916,100$ \\
5 & $1,707,939$ & 153,619 & $262,371,881,241$ & $2,917,055,627,721$ & $23,598,797,161$ \\
6 & $1,700,934$ & 158,776 & $270,067,496,784$ & $2,893,176,472,356$ & $25,209,818,176$ \\
7 & $1,696,086$ & 164,058 & $278,256,476,988$ & $2,876,707,719,396$ & $26,915,027,364$ \\
8 & $1,633,525$ & 142,717 & $233,131,787,425$ & $2,668,403,925,625$ & $20,368,142,089$ \\
9 & $1,632,812$ & 137,224 & $224,060,993,888$ & $2,666,075,027,344$ & $18,830,426,176$ \\
10 & $1,661,134$ & 139,112 & $231,083,673,008$ & $2,759,366,165,956$ & $19,352,148,544$ \\
11 & $1,679,145$ & 151,507 & $254,402,221,515$ & $2,819,527,931,025$ & $22,954,371,049$ \\
12 & $1,628,937$ & 153,256 & $249,644,368,872$ & $2,653,435,749,969$ & $23,487,401,536$ \\
\hline $\mathbf{\Sigma}$ & $\mathbf{1 9 , 9 6 2 , 3 6 5}$ & $\mathbf{1 , 7 7 1 , 7 7 2}$ & $\mathbf{2 , 9 4 9 , 4 1 0 , 0 7 9 , 3 9 6}$ & $\mathbf{3 3 , 2 1 9 , 8 6 1 , 8 3 7 , 2 8 3}$ & $\mathbf{2 6 2 , 4 7 3 , 4 0 9 , 7 5 6}$ \\
\hline
\end{tabular}

Sumber : Pengolahan data 
Scatter Diagram digunakan untuk melihat hubungan (korelasi) dari suatu faktor penyebab yang berkesinambungan terhadap karakteristik kualitas. Perhitungan korelasi dilakukan untuk mengetahui hubungan antara cacat jahitan miring dengan jumlah produksi dapat dilihat pada tabel 6 diatas.

Perhitungan analisis regresi linier pada tabel 6 dapat ditunjukkan sebagai berikut :

$$
\begin{aligned}
r & =\frac{\mathrm{n}\left(\sum \mathrm{xy}\right)-\left(\sum \mathrm{x}\right)\left(\sum \mathrm{y}\right)}{\sqrt{\left[\mathrm{n}\left(\sum \mathrm{x}^{2}\right)-\left(\sum \mathrm{x}\right)^{2} \mid \mathrm{n}\left(\sum \mathrm{y}^{2}\right)-\left(\sum \mathrm{y}\right)^{2}\right.}} \\
r & =\frac{12(2.949 .410 .079 .396)-19.962 .365(1.771 .772)}{\sqrt{\left[12(33.219 .861 .837 .283)-(19.962 .365)^{2} \mid 12(262.473 .409 .756)-(1.771 .772)^{2}\right.}} \\
r & =0,6251
\end{aligned}
$$

Gambar 3. Scatter Diagram Jahitan Miring vs Jumlah Produksi

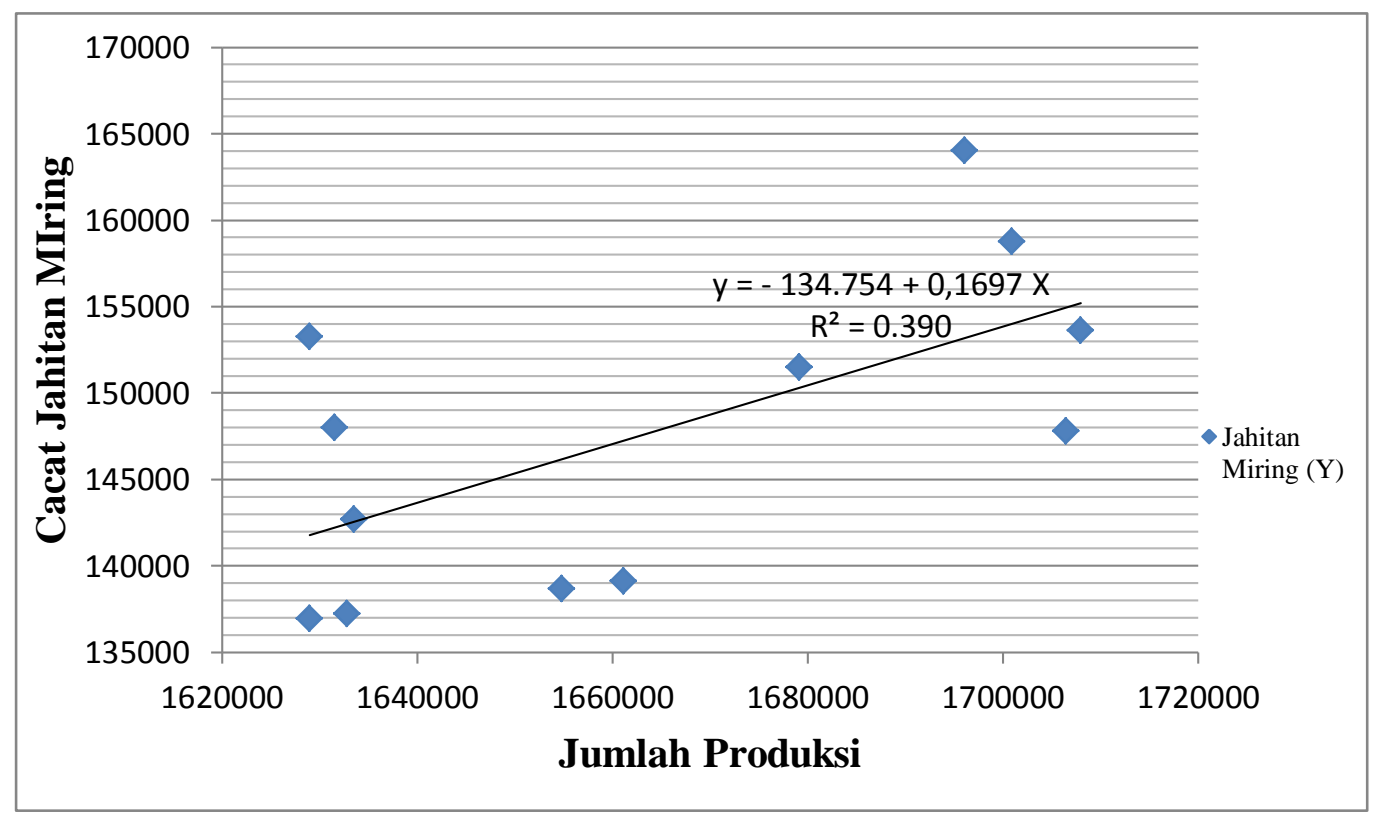

Sumber : Pengolahan data

Persamaan garis regresi linier yang diperoleh adalah : $\mathrm{Y}=-134.754+$ 0,1697X. Berdasarkan pada grafik diatas diperoleh nilai $\mathrm{R}^{2}=0,390$ atau $39 \%$, artinya jahitan miring memberikan kontribusi sebesar 39\% terhadap kegagalan produksi, sedangkan sisanya dipengaruhi oleh variabel lain yang tidak disebutkan dalam penelitian ini. 
Tabel 7. Perhitungan Korelasi Cetakan Miring vs Jumlah Produksi

\begin{tabular}{cccccc}
\hline No. & $\begin{array}{c}\text { Jumlah } \\
\text { Produksi } \\
(\mathbf{X})\end{array}$ & $\begin{array}{c}\text { Cetakan } \\
\text { Miring } \\
(\mathbf{Y})\end{array}$ & $\mathbf{X} * \mathbf{Y}$ & $\mathbf{X}^{\mathbf{2}}$ & $\mathbf{Y}^{\mathbf{2}}$ \\
\hline 1 & $1,628,983$ & 107,328 & $174,835,487,424$ & $2,653,585,614,289$ & $11,519,299,584$ \\
2 & $1,706,511$ & 118,185 & $201,684,002,535$ & $2,912,179,793,121$ & $13,967,694,225$ \\
3 & $1,631,559$ & 118,378 & $193,140,691,302$ & $2,661,984,770,481$ & $14,013,350,884$ \\
4 & $1,654,800$ & 109,050 & $180,455,940,000$ & $2,738,363,040,000$ & $11,891,902,500$ \\
5 & $1,707,939$ & 123,979 & $211,748,569,281$ & $2,917,055,627,721$ & $15,370,792,441$ \\
6 & $1,700,934$ & 129,135 & $219,650,112,090$ & $2,893,176,472,356$ & $16,675,848,225$ \\
7 & $1,696,086$ & 134,417 & $227,982,791,862$ & $2,876,707,719,396$ & $18,067,929,889$ \\
8 & $1,633,525$ & 113,077 & $184,714,106,425$ & $2,668,403,925,625$ & $12,786,407,929$ \\
9 & $1,632,812$ & 107,585 & $175,666,079,020$ & $2,666,075,027,344$ & $11,574,532,225$ \\
10 & $1,661,134$ & 109,473 & $181,849,322,382$ & $2,759,366,165,956$ & $11,984,337,729$ \\
11 & $1,679,145$ & 121,867 & $204,632,363,715$ & $2,819,527,931,025$ & $14,851,565,689$ \\
12 & $1,628,937$ & 123,615 & $201,361,047,255$ & $2,653,435,749,969$ & $15,280,668,225$ \\
\hline $\mathbf{\Sigma}$ & $\mathbf{1 9 , 9 6 2 , 3 6 5}$ & $\mathbf{1 , 4 1 6 , 0 8 9}$ & $\mathbf{2 , 3 5 7 , 7 2 0 , 5 1 3 , 2 9 1}$ & $\mathbf{3 3 , 2 1 9 , 8 6 1 , 8 3 7 , 2 8 3}$ & $\mathbf{1 6 7 , 9 8 4 , 3 2 9 , 5 4 5}$ \\
\hline
\end{tabular}

Sumber : Pengolahan data

Perhitungan analisis regresi linier pada tabel 7 dapat ditunjukkan sebagai berikut :

$r=\frac{\mathrm{n}\left(\sum \mathrm{xy}\right)-\left(\sum \mathrm{x}\right)\left(\sum \mathrm{y}\right)}{\sqrt{\left[\mathrm{n}\left(\Sigma \mathrm{x}^{2}\right)-(\Sigma \mathrm{x})^{2} \mid \mathrm{n}\left(\Sigma \mathrm{y}^{2}\right)-(\Sigma \mathrm{y})^{2}\right.}}$

$r=\frac{12(2.357 .720 .513 .291)-19.962 .365(1.416 .089)}{\sqrt{\left[12(33.219 .861 .837 .283)-(19.962 .365)^{2} \mid 12(167.984 .329 .545)-(1.416 .089)^{2}\right.}}$

$r=0,6249$

Gambar 4. Scatter Diagram Cetakan Miring vs Jumlah Produksi

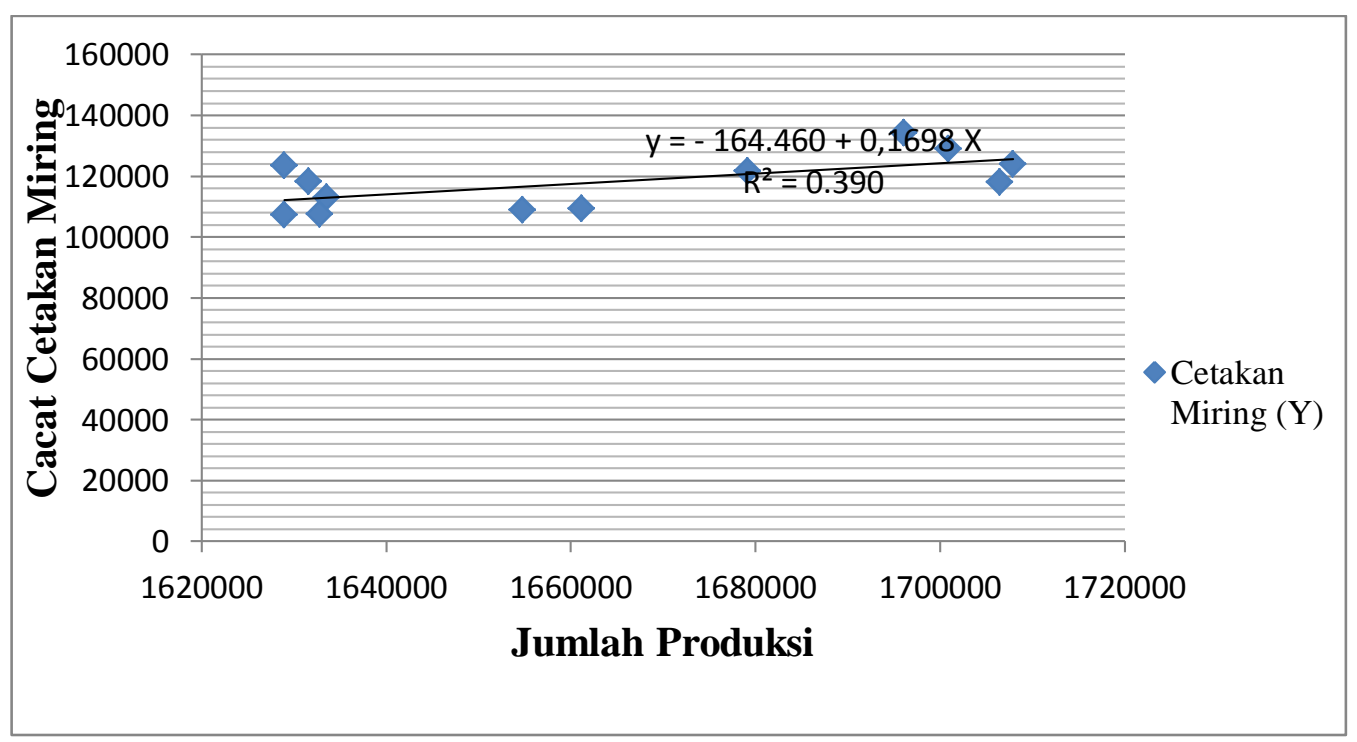

Sumber : Pengolahan data 
Persamaan garis regresi linier yang diperoleh adalah $: \mathrm{Y}=-164.460+0,1698$ X. Nilai $R^{2}=0,390$ atau $39 \%$. artinya jahitan miring memberikan kontribusi sebesar 39\% terhadap kegagalan produksi (produk reject), sedangkan sisanya dipengaruhi oleh variabel lain yang tidak disebutkan dalam penelitian ini.

Berdasarkan hasil perhitungan diatas, diperoleh nilai korelasi jahitan miring dengan jumlah produksi sebesar 0,6251 dan nilai korelasi cetakan miring dengan jumlah produksi sebesar 0,6249 artinya adanya hubungan yang kuat (positif) antara kedua jenis cacat dengan jumlah produksi.

\section{Tahap Improve (Memperbaiki)}

Setelah semua penyebab masalah kualitas teridentifikasi, maka tahap selanjutnya adalah memberikan solusi atas permasalahan tersebut.

1. Komposisi bahan baku harus selalu diperhatikan dan pengawasan serta pengontrolan yang ketat terhadap karyawan yang tidak mematuhi SOP yang berlaku disetiap tahapan proses produksi untuk meminimalkan karung goni plastik yang cacat.

2. Perbaikan mesin yang rusak atau mengalami kemacetan khususnya pada bagian gulungan mesin pada saat pencetakan karung goni plastik, kemudian melakukan perawatan yang berkala dan intensif pada setiap mesin yang ada khususnya pada jarum jahit otomatis yang sudah mulai aus dan menggantinya dengan mesin yang baru.

3. Melakukan pengawasan rutin terhadap setiap metode kerja karyawan yang tidak teliti dan ceroboh pada bagian produksi serta tidak disiplin dalam bekerja.

4. Memberikan pelatihan khusus atau training mengenai pekerjaan masingmasing bidang serta pelatihan khusus untuk pengembangan diri kepada setiap karyawan, baik untuk karyawan yang baru, maupun untuk karyawan lama. Serta dengan berkala melakukan uji kompetensi kepada karyawan guna untuk menguji kemampuan setiap karyawan.

\section{Tahap Control (Mengontrol)}

Pada tahap ini dilakukan tindakan pengendalian dari hasil-hasil peningkatan six sigma. Adapun tahapan pengendalian sebagai proyek six sigma yang menekankan pada tindakan perbaikan, dimana tindakan yang dilakukan sebagai pertimbangan bagi perusahaan yaitu:

1.Melakukan pembersihan dan pemeriksaan terhadap semua mesin dan peralatan khususnya untuk mesin jahit otomatis, mesin pencetak (printing) dan 
gulungan mesin serta peralatan produksi sebelum dan sesudah proses produksi.

2. Melakukan pengawasan terhadap setiap komposisi bahan baku, dan karyawan bagian produksi agar mutu produk tetap terjaga.

3. Meningkatkan pengamatan pada mesin jahit otomatis khususnya pada jarum mesin jahit yang sudah mulai aus untuk segera diganti agar karung terjahit dengan sempurna.

4. Memastikan gulungan pada mesin cetak (printing) tidak macet, dan meletakan dengan baik dan benar (lurus) karung yang akan dimasukkan kedalam mesin cetak agar hasil cetakan jelas dan tidak miring.

5. Melakukan pencatatan produk cacat setiap hari dari masing-masing jenis cacat dan mesin yang dilakukan oleh karyawan, dan melaporkannya kepada supervisor untuk dilanjutkan kepada manajer produksi.

6. Melakukan pemeriksaan (check body) terhadap para pekerja yang dilakukan oleh satpam untuk menghindari adanya kehilangan atau kejadian yang tidak diinginkan oleh perusahaan.

\section{SIMPULAN}

Dari penelitian yang sudah dilakukan, maka dapat ditarik beberapa kesimpulan adalah sebagai berikut: terdapat 2 jenis kecacatan dalam produksi karung goni plastik dan dominan berpengaruh terhadap jumlah maupun kualitas produksi karung goni plastik diantaranya adalah jahitan miring, dengan persentase cacat perbulan antara 8,37\% 9,67\% dengan rata-rata tingkat kecacatan pertahunnya sebesar $8,87 \%$ dan cetakan miring dengan persentase cacat perbulan antara $6,59 \%-7,93 \%$ dengan rata-rata tingkat kecacatan pertahunnya sebesar 7,09\%. Faktor-faktor penyebab kecacatan yang terjadi pada umumnya sama pada semua jenis kecacatan produksi karung goni plastik, baik cacat karena jahitan miring maupun cacat karena cetakan miring. Adapun faktor-faktor yang berpengaruh secara signifikan diantaranya adalah: komposisi bahan baku yang tidak sesuai, kondisi mesin yang sudah aus dan berumur akibat kurangnya melakukan pengecekan dan perawatan berkala, kelalaian operator serta kurangnya keterampilan yang dimiliki dan metode kerja yang salah. Berdasarkan hasil pengukuran peta kontrol $\mathrm{P}$ didapatkan cacat yang terjadi masih dalam batas kontrol perusahaan, baik untuk cacat jahitan miring maupun cacat cetakan miring. Namun berdasarkan hasil analisis regresi linier sederhana dapat disimpulkan bahwa adanya hubungan yang kuat 
(positif) antara jumlah produksi terhadap jumlah produk cacat yang berpengaruh terhadap kualitas produk. Nilai koefisien korelasi antara jumlah produksi dengan cacat jahitan miring adalah sebesar 0,6251 dengan persentase pengaruh cacat terhadap jumlah produksi sebesar $\mathrm{R}^{2}=0,390$ atau 39\%. Nilai koefisien korelasi antara jumlah produksi dengan cacat cetakan miring adalah sebesar 0,6249 dengan persentase pengaruh cacat terhadap jumlah produksi sebesar $\mathrm{R}^{2}=0,390$ atau $39 \%$. Artinya cacat jahitan miring dan cacat cetakan miring masing-masing memberikan kontribusi sebesar 39\% terhadap kegagalan (produk reject), sedangkan sisanya dipengaruhi oleh variabel lain yang tidak disebutkan dalam penelitian ini.

\section{DAFTAR PUSTAKA}

Gaspersz, V. (2002). Pedoman Implementasi Program Six Sigma Terintegrasi dengan ISO 9001,2000,MBNQA dan HACCP. Jakarta: PT. Gramedia Pustaka Utama.

Ginting, R. (2007). Sistem Produksi. Yogyakarta: Graha Ilmu.

Johnson Saragih, Winnie Septianie, Yuliana. (2011). Pengukuran Lean Six Sigma Pada Perusahaan (Studi Kasus di PT. Indo Mitra Pratama). Proceeding Seminar Nasional
Teknik Industri dan Kongres BKSTI, Hal. IIB-328.

Muis, S. (2011). Metodologi 6 Sigma (Menciptakan Kualitas Produk Kelas Dunia) Edisi Pertama. Yogyakarta: Graha Ilmu.

Remba Yanuar Efranto,Falih Suaedi. (2011). Pendekatan Lean Six Sigma Sebagai Metode Analisis Kualitas Pelayanan Publik Pemerintah. Proceeding Seminar Nasional Teknik Industri dan Kongres BKSTI VI , Hal.IIA-186.

Sugiyono. (2014). Metode Penelitiann Manajemen, Cetakan ketiga, Bandung: Alfabeta.

Yogi Yusuf Wibisono, Theressa Suteja. (2013). Implementasi Metode DMAIC-Six Sigma dalam Perbaikan Mutu di Industri Kecil Menengah:Studi Kasus Perbaikan Mutu Produk Spring Adjuster di PT.X. Seminar Nasional IENACO, ISSN:2337-4349. 